\title{
Solvothermal synthesis of nanoscale disc-like gadolinium doped magnesium zirconate for highly efficient photocatalytic degradation of rhodamine $B$ in water
}

\author{
S. Akshatha ${ }^{1} \cdot$ S. Sreenivasa ${ }^{1}$ (D) - L. Parashuram ${ }^{1,2} \cdot$ V. Udaya Kumar $^{3} \cdot$ Tadimety Madhu Chakrapani Rao $^{4}$. \\ Sandeep $\mathrm{Kumar}^{5,6} \cdot$ M. S. Raghu ${ }^{2}$
}

Received: 24 January 2020 / Accepted: 2 April 2020 / Published online: 10 April 2020

(c) Springer Nature Switzerland AG 2020

\begin{abstract}
Highly ordered nanoscale disc-like cubic gadolinium doped magnesium zirconate $\left(\mathrm{Gd}: \mathrm{MgZrO}_{3}\right)$ was synthesized by facile solvothermal route. The reaction time was found to be crucial in determining the final morphology of disc-like $\mathrm{Gd}: \mathrm{MgZrO}_{3}$. After studying the particles from time-dependent experiments, it is observed that, the formation of disc-like particles involved a complex process, in which rod-like or agglomerate particles were favorably formed after the initial thermal treatment. Owing to the chemical instability, they would turn into disc-like particles. After calcination, the generated product possessed good photocatalytic performance for the degradation of Rhodamine $B\left(50 \mathrm{mg} \mathrm{I}^{-1}\right)$ under UV light irradiation in contrast to morphologies of $\mathrm{Gd}_{\mathrm{O}} \mathrm{MgZrO}_{3}$ and other related state-of-the-art photocatalysts (e.g., $\mathrm{TiO}_{2}$, $\mathrm{ZnO}, \mathrm{WO}_{3}, \mathrm{BiVO}_{4}, \mathrm{Fe}_{2} \mathrm{O}_{3}$, and $\mathrm{g}-\mathrm{C}_{3} \mathrm{~N}_{4}$ ). The catalyst could be used for five cycles, maintaining its efficiency above $94.2 \%$. These capacities made the disc-like $\mathrm{Gd}: \mathrm{MgZrO}_{3}$ a potential candidate for polluted water treatment. Also, the underlying photocatalysis mechanism of $\mathrm{Gd}: \mathrm{MgZrO}_{3}$ was proposed through radical trapping experiments.
\end{abstract}

Keywords Gadolinium doped zirconia · Photocatalysis · Rhodamine B degradation · Nanoscale disc

\section{Introduction}

Industrial dye effluents are one of the major sources of water contamination and indicate increasing threat to the environment [1]. Textile and dyestuff industries are continuosly releasing the toxic, chemically stable, complex and non-biodegradable dye contaminants into the water bodies. Hence, removal of organic pollutants in water requires devising versatile strategies [2]. Researchers have demonstrated various strategies like adsorption of dye effluents on activated carbon, coagulation, membrane purification and reverse osmosis for the removal of dye effluents from water. However, all these methods are tedius and produce secondary contaminants, which has to be further treated to avoid pollution. Hence, photocatalytic treatment of dye effluents is one of the most effective approach for the removal of organic contaminants in water [3-6]. In this path, metal oxide nanomaterials showed excellent photocatalytic activity for the removal of organic dyes due to their high physical, chemical properties, high surface area, high surface energy and quantum confinement effects compared to the counter bulk materials. In the past decade, many catalysis researchers attempted to develop

$\triangle$ S. Sreenivasa, drsreenivasa@yahoo.co.in; $\square$ L. Parashuram | ${ }^{1}$ Department of Studies and Research in Organic Chemistry, Tumkur University, Tumkur 572101, India. ${ }^{2}$ Department of Chemistry, New Horizon College of Engineering Affiliated To VTU, Bangalore 560087, India. ${ }^{3}$ Department of Chemistry, Siddaganga Institute of Technology Affiliated To VTU, Tumkur 572102, India. ${ }^{4}$ Tadimety Aromatics Pvt. Ltd, Hirehally Industrial Area, Tumkur 572168, India. ${ }^{5}$ Raman Research Institute, C V Raman Avenue, Bangalore 560080, India. ${ }^{6}$ Department of Chemistry, Nitte Meenakshi Institute of Technology, Yelahanka 560064, India. 
heterogeneous photocatalysts with bimetallic and trimetallic modifications to improve charge transport properties, electronic structure and porosity for enhanced photocatalytic performance [7-10]. In addition to these properties it is a known fact that, these metal oxides are nature abundant, they show excellent stability under various conditions. However, the major disadvantage of using metal oxide photocatalysts is fast recombination of photogenerated electron-hole system, this leads to ineffective generation of free radicals required for the photo degradation process. This problem can be overcome by creating $p-n$ junction or suitably tuning the band energies of the material. Till date, number of metal oxide photocatalysts have been developed with multi metallic composition and structural features [11-15]. Nanoscale zirconia is an excellent material in the field of catalysis [16], electrochemical sensor [17], photocatalysis [18], solid acid catalyst [19] and fuel cells [20] etc., these properties have imparted for zirconia due to its high surface area, porosity, wide band gap, chemical inertness, thermal stability, abundancy and low cost. These properties of zirconia makes it a material of choice for most of the catalysis researchers. Introducing the metal ions like $\mathrm{Mg}, \mathrm{Ca}, \mathrm{Bi}, \mathrm{Sm}, \mathrm{Gd}$ with different oxidation state will induce flexibility in the band structure of zirconia. These ions can result in the formation of oxygen vacancy defects thereby altering the electronic, thermal and catalytic properties of zirconia. Also, these dopant ions will effectively control the recombination of photogenerated charge carriers and interfacial charge transfer, as faster recombination is one of the drawbacks of zirconia when it is used in photochemical processes. Out of all these dopant ions $\mathrm{Mg}$ draws considerable interest as, magnesium oxide at nano scale posses high defect centers which leads to the formation of $\mathrm{O}_{2}{ }^{-}$, this enhances the photocatalytic performance of zirconia. Further a rare earth dopant gadolinium is localized with half filled $f$-orbitals act as trap centers for charge carrieres and reduce the rate of electron-hole recombination, thus improve the photocatalytic efficiency. There are many methods reported for the synthesis of nanoscale zirconia like co-precipitation [21], sol-gel [22], solid state reaction [23], hydrothermal [24] and solvothermal [25] etc., Out of all the methods solvothermal method is superior in terms of great control over particle morphology and particle size. Keeping in mind all the challenges that are mentioned in the above discussion, herein we report a simple and facile method for the synthesis of a trimetallic gadolinium doped magnesium zirconate ( $\left.\mathrm{Gd}: \mathrm{MgZrO}_{3}\right)$ via solvothermal process. A detailed characterization of thus prepared material has been carried out, photoluminescene spectroscopy has been used to probe into the defect states of the material. Further $\mathrm{Gd}: \mathrm{MgZrO}_{3}$ has been used for the photocatalytic degradation of Rhodamine B in water. Hence, we propose the novel $\mathrm{Gd}: \mathrm{MgZrO}_{3}$ as a promising candidate in the environmental remediation.

\subsection{Preparation of Gd:MgZrO}

Disc like $\mathrm{Gd}: \mathrm{MgZrO}_{3}(4 \mathrm{~mol} \%)$ has been prepared by solvothermal method. In the typical procedure, known quantity of the precursor $\mathrm{Gd}_{2} \mathrm{O}_{3}$ has been digested in conc. nitric acid and the excess nitric acid has been quenched, thus obtained gadolinium nitrate is mixed with $\mathrm{Mg}\left(\mathrm{NO}_{3}\right)_{2} \cdot 6 \mathrm{H}_{2} \mathrm{O}$ and $\mathrm{ZrO}\left(\mathrm{NO}_{3}\right)_{2} \cdot \mathrm{xH}_{2} \mathrm{O}$ (46 mol\%:50 mol\%) in $60 \mathrm{ml}$ of solvent (Water:DMF-1:1 v/v). The resultant solution was ultrasonicated to get homogeneous solution and loaded into a teflon lined stainless steel autoclave and subjected to solvothermal treatment at $180^{\circ} \mathrm{C}$ for a given period of time (24-72 h). The supernatent liquid in the final product has been removed carefully by decantation, the product was washed thrice with DMF $(3 \times 10 \mathrm{ml})$ and finally with chloroform. Thus obtained solid was dried at $120^{\circ} \mathrm{C}$, calcinated at $800^{\circ} \mathrm{C}$ and stored under vacuum dessication till further use. Following the similar experimental conditions 1, 2, 3 and 5 mol\% gadolinium doped magnesium zirconate samples were prepared.

\section{Results and discussions}

FTIR spectra were recorded using Bruker-Alpha spectrometer with specrtral grade $\mathrm{KBr}$. Powder X-ray diffraction data was recorded using Rigaku smart lab with $\mathrm{Cu}-\mathrm{Ka}$ as the radiation source. Thermogravimetric analysis has been carried out using PerkinElmer, USA, TGA4000 instrument. BET surface characterization was done using ASAP-Micromeritics porosimeter. Diffuse reflectance spectra (DRS) of the samples were recorded using PerkinElmer UV Winlab Lambda 35 instrument. The morphology and structure of the samples were inspected using Zeiss FESEM instrument. XPS analysis was done using PHI 5000 Versa Prob II,FEI Inc. ESR spectra was obtained by an A300 electron spin-resonance spectrometer (Bruker, Ettlingen, Germany) at $3450 \mathrm{G}$ and $9.86 \mathrm{GHz}$. Photocatalytic activity testing was done using Schimadzu-1600 UV-Vis spectrophotometer, Photoluminescence measurements were done using Agilent Cary eclipse Photoluminescent spectrofluoremeter equipped with xenon lamp as the source of radiation.

FTIR spectrum of as prepared Gd:MgZrO 3 (1-5 mol\% Gd) has been shown in Fig. 1. A broad peak around $335-765 \mathrm{~cm}^{-1}$ has been attributed to the presence of vibration modes of metal oxygen bonds ( $\mathrm{Gd}-\mathrm{O}, \mathrm{Mg}-\mathrm{O}$ and $\mathrm{Zr}-0$ ). Wide peak around $800-1000 \mathrm{~cm}^{-1}$ will be attributed to the hydroxide form of $\mathrm{Mg}$ and $\mathrm{Zr}$. The peak at $1100 \mathrm{~cm}^{-1}$ 


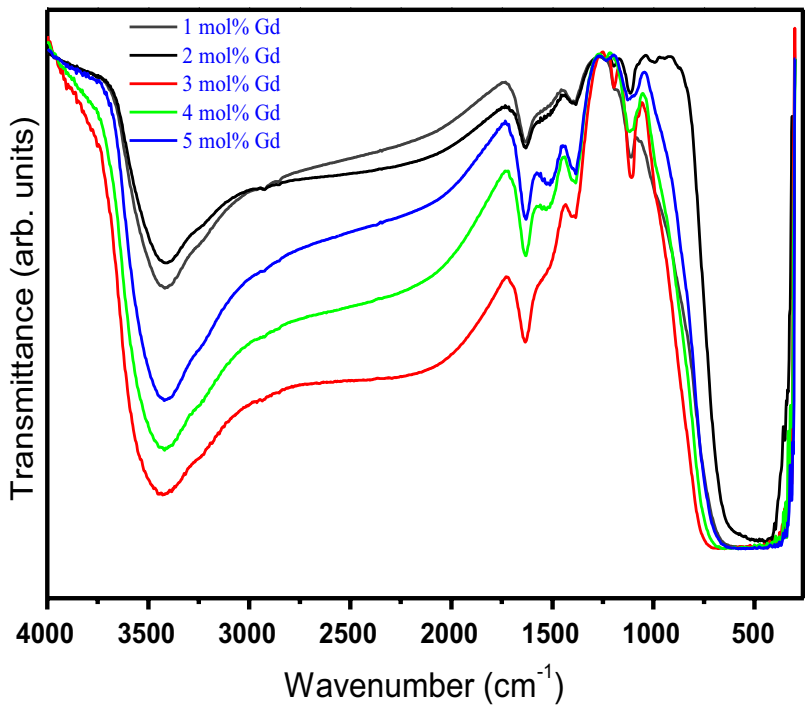

Fig. 1 FTIR spectrum of $\mathrm{Gd}: \mathrm{MgZrO}_{3}(1-5 \mathrm{~mol} \%)$

is due to the $\mathrm{Mg}-\mathrm{O}-\mathrm{Zr}$ asymmetric strechings. Peak at $1634 \mathrm{~cm}^{-1}$ is assigned to the bending mode vibration of water molecules and a significant broad peak at $3420 \mathrm{~cm}^{-1}$ attributed to the streching vibrations of $-\mathrm{OH}$ involving $\mathrm{Mg}-\mathrm{OH}$ and $\mathrm{Zr}-\mathrm{OH}$. The crystallinity and the phase formation of $\mathrm{Gd}: \mathrm{MgZrO}_{3}$ were studied by X-ray diffraction analysis and is shown in Fig. 2. The patterns clearly indicated dominant cubic zirconia phase with small contribution of cubic magnesium oxide, the structure was in good agreement with the standard JCPDS card No. 27-997 and 1-1235 respectively. No other impurity peaks were visualized in the XRD, this indicates good purity of the prepared material. Upon doping beyond $4 \%$ of gadolinium, the XRD peak

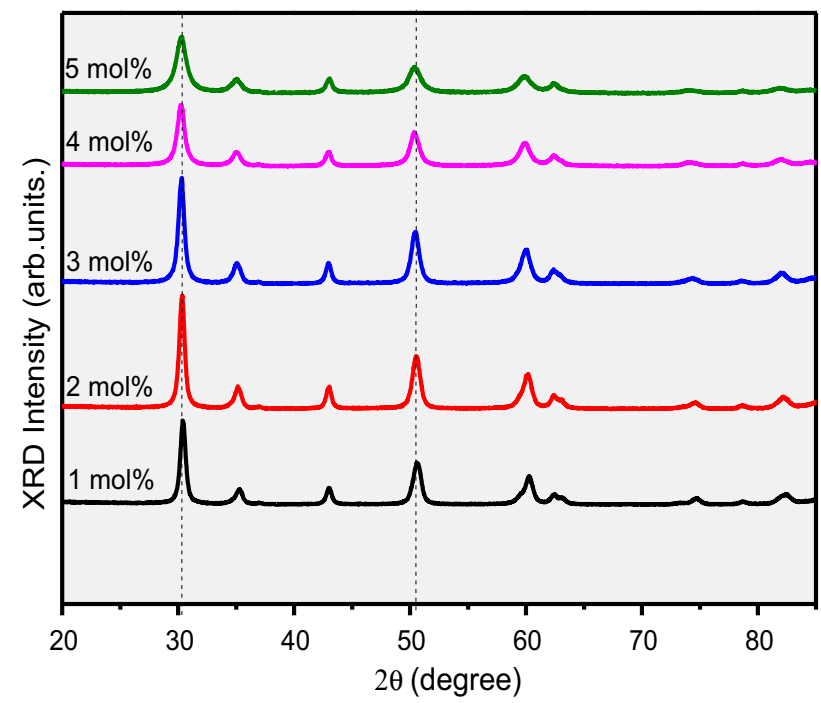

Fig. 2 XRD patterns of Gd:MgZrO 3 (1-5 mol\%) intensity has decreased, this is due to the fact the percolation of dopant ions results in lattice expansion, which consequently induces micro strain and tensile stress in the material. Introducing gadolinium into magnesium zirconate increases its oxygen vacancy defects, these vacancies will reduce the crystal density and expand the lattice. Also, there were no peaks corresponding to gadolinium were observed in the XRD pattern clearly indicates high ordered dispersion of gadolinium in the sea of magnesium zirconate. Scherrer method was used to calcualted the average crystallite size of $\mathrm{Gd}: \mathrm{MgZrO}_{3}$, it was calculate to be $12-16 \mathrm{~nm}$. The microstrain and dislocation density calculated to be $2.3 \times 10^{-3}$ and 4.7 for $\mathrm{Gd}: \mathrm{MgZrO}_{3}(4 \%)$.

To investigate the thermal stability of the solvothermal synthesized material, it was subjected to thermo gravimetric analysis (TGA) and is shown in Fig. 3. From the TGA analysis it is evident that, the material lost a percentage weight of 6.1 over ambient temperature to $800^{\circ} \mathrm{C}$. Beyond this temperature the material was almost stable, the gradual lose in weight was attributed to the lose of surface adsorbed water, decomposition of any hydroxide form of material and subsequent phase stabilization of the material, hence the temperature for calcination of the material was opted to be $800^{\circ} \mathrm{C}$.

To obtain information about pore structure, pore volume and specific surface area of $\mathrm{Gd}: \mathrm{MgZrO}_{3}(4 \%), \mathrm{BET}$ surface area and $\mathrm{BJH}$ pore size measurements were carried out and the corresponding $\mathrm{N}_{2}$ adsorption-desorption hysterisis curve has been shown in Fig. 4. From the figure it is clear that, $\mathrm{Gd}: \mathrm{MgZrO}_{3}$ shows type IV adsorption isotherm with $\mathrm{H} 1$ type hysterisis, this shows the material is mesoporous in nature with pore distribution centered at $15 \mathrm{~nm}$. The BET surface area calculated to be $162 \mathrm{~m}^{2} \mathrm{~g}^{-1}$, to understand the variation surface parameters, BET analysis

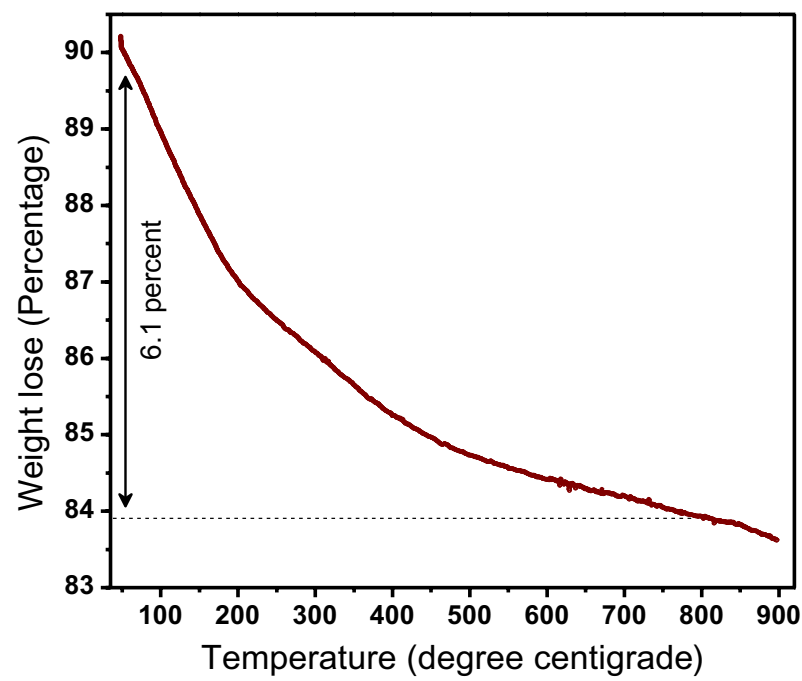

Fig. 3 Thermogravimetric analysis of $\mathrm{Gd}: \mathrm{MgZrO}_{3}(4 \%)$ 

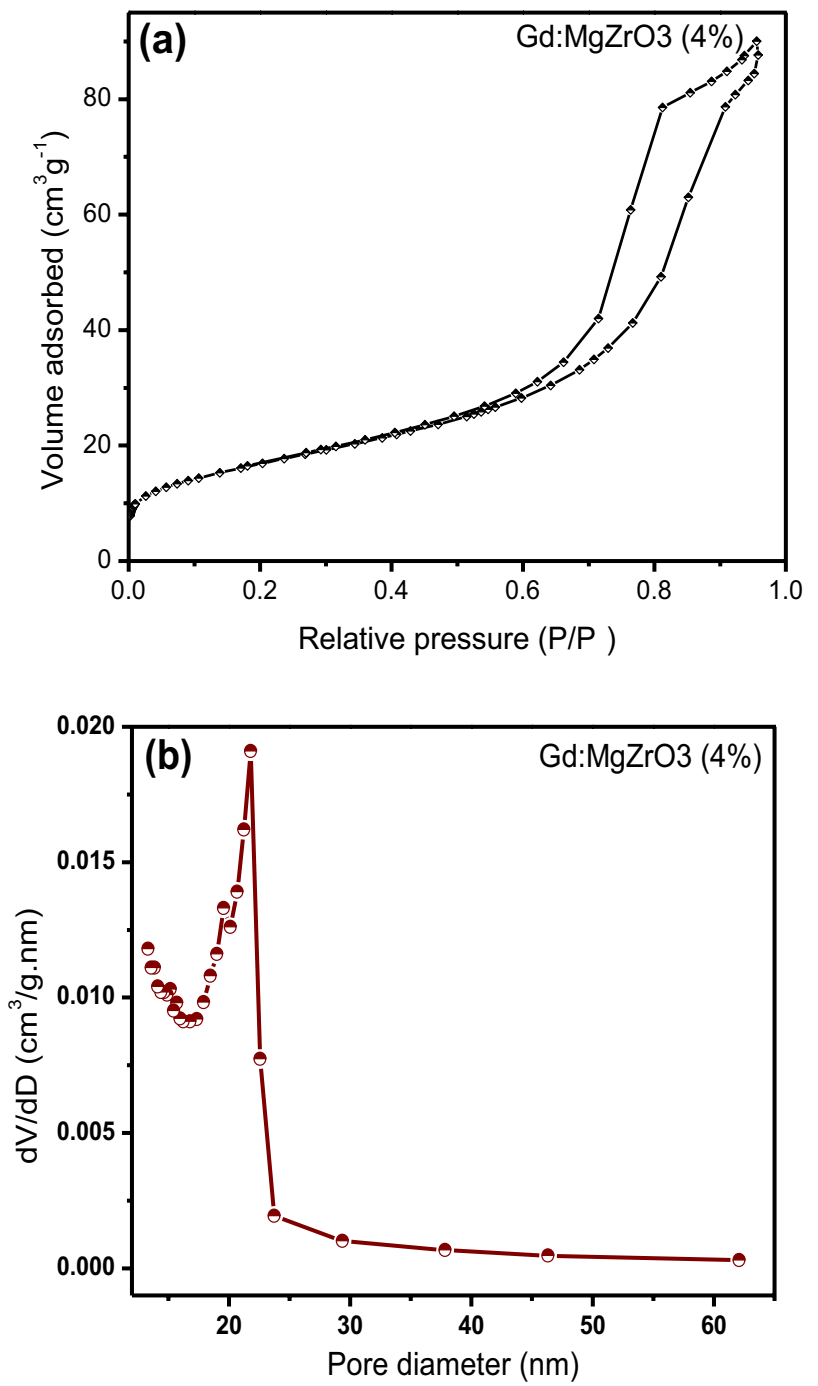

Fig. 4 a $\mathrm{N}_{2}$ adsorption-desorption isotherm of $\mathrm{Gd}: \mathrm{MgZrO}_{3}(4 \%)$. b $\mathrm{BJH}$ pore distribution plot of $\mathrm{Gd}: \mathrm{MgZrO}_{3}(4 \%)$

Table 1 Results of BET analysis of gadolinium doped magnesium zirconate

\begin{tabular}{lllc}
\hline Sample & $\begin{array}{l}\text { Specific surface } \\
\text { area }\left(\mathrm{m}^{2} \mathrm{~g}^{-1}\right)\end{array}$ & $\begin{array}{l}\text { Pore volume } \\
\left(\mathrm{cm}^{3} \mathrm{~g}^{-1}\right)\end{array}$ & $\begin{array}{l}\text { Average } \\
\text { pore size } \\
(\mathrm{nm})\end{array}$ \\
\hline $\mathrm{Gd}: \mathrm{MgZrO}_{3}(1 \%)$ & 156 & 0.33 & 9.23 \\
$\mathrm{Gd}: \mathrm{MgZrO}_{3}(2 \%)$ & 152 & 0.36 & 10.02 \\
$\mathrm{Gd}: \mathrm{MgZrO}_{3}(3 \%)$ & 142 & 0.38 & 10.45 \\
$\mathrm{Gd}: \mathrm{MgZrO}_{3}(4 \%)$ & 162 & 0.35 & 9.65 \\
$\mathrm{Gd}: \mathrm{MgZrO}_{3}(5 \%)$ & 160 & 0.33 & 9.54 \\
\hline
\end{tabular}

of all the samples has been carried out and presented in Table 1. It is observed from the analysis that, increasing the dopant concentration from 1-3 mol\% has decreased the specific surface area owing to strong crystallization of material (as evident from XRD). Further increase to $4 \mathrm{~mol} \%$ improved the surface area to $162 \mathrm{~m}^{2} \mathrm{~g}^{-1}$, this is attributed to the control of cluster formation at optimum dopant concentration and production of highly specific structures. This high surface area is due to the incorporation of dopants like gadolinium, which restricts the agglomeration and formation of clusters. This high surface area also develops more defect centers, therby more photoactive sites for effective degradation of dye. Diffuse relectance spectroscopy (DRS) and Kubelka-Munk function was used to know the band gap of Gd:MgZrO $3(1-5 \mathrm{~mol} \%)$ and were shown in Fig. $5 a$, b. There is slight variation in the band gap of all the five samples but are within $5.45 \mathrm{eV}$. These variations in the band gap was attributed to the lattice defects, unbalanced charges and order-disorderness created in the material due to the incorporation of gadolinium ions. The
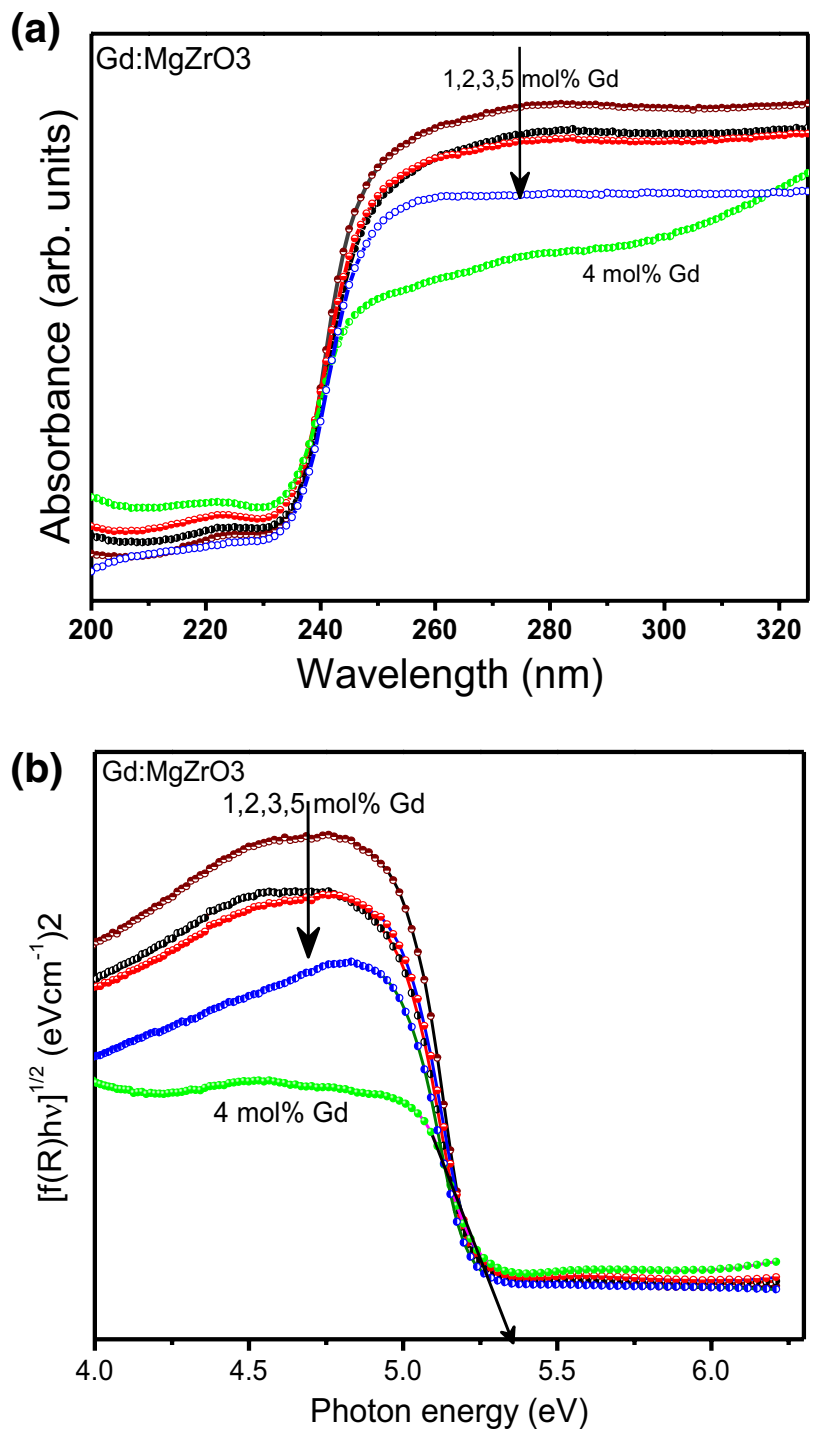

Fig. 5 a Diffuse reflectance spectra of $\mathrm{Gd}: \mathrm{MgZrO}_{3}$ (1-5\%). b Kubelka-Munk energy band gap plot of $\mathrm{Gd}_{\mathrm{MgZrO}}(1-5 \mathrm{~mol} \%)$ 
band gap of Gd:MgZrO 3 (4 mol\%) was found to be $5.38 \mathrm{eV}$. To understand the morphology and microstructure, FESEM images of $\mathrm{Gd}: \mathrm{MgZrO}_{3}$ (4 mol\%) were recorded as shown in Fig. 6. figure shows the SEM images of $\mathrm{Gd}: \mathrm{MgZrO}_{3}$
(4 mol\%) processed for $12,24,48$ and $72 \mathrm{~h}$ respectively. The material processed for $12 \mathrm{~h}$ solvothermal treatment clearly shows particles with nearly rod like irregular agglomerate structures (Fig. 6a), these structures would
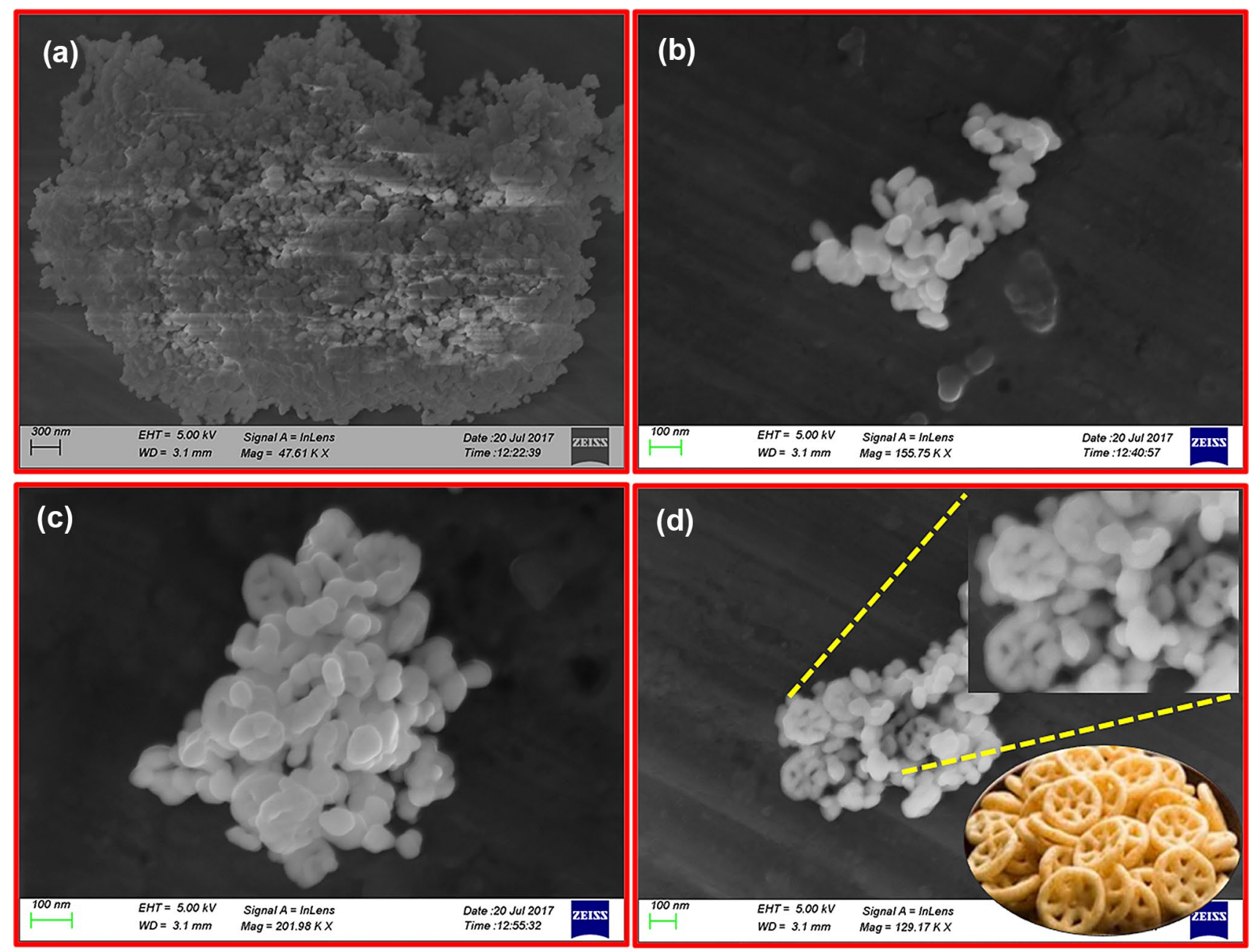

(e)

Spectrum 3

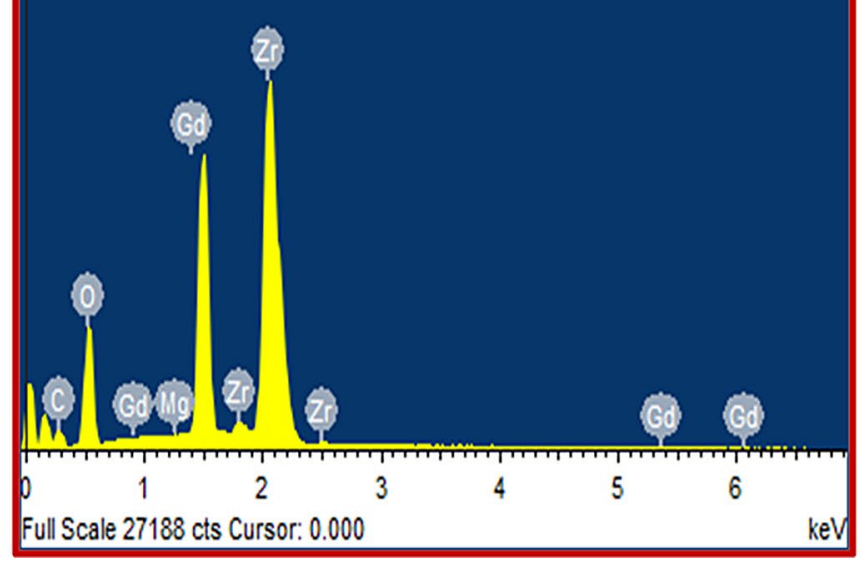

Fig. 6 FESEM images of solvothermal treated Gd:MgZrO 3 (4\%)-a For 12 h, b 24 h, c 48 h, d 72 h 
self assemble, cross to form dumble shaped particles when solvothermal processed for $24 \mathrm{~h}$ (Fig. 6b). These dumble shaped particle further assemble to give regular circular shaped clusters (Fig. $6 \mathrm{c}$ ). Owing to the instability of these clusters, they align to give rise to compact disc like structures (Fig. 6d-The inset of the figure shows enlarged image showing disc structures and a representative image also been provided for comparison). From the SEM investigation it is clear that, formation of disc like structure takes place when the precursors were solvothermal treated for a duration of $72 \mathrm{~h}$ only. Also it is clearly evident that long duration solvothermal treatment reduced the agglomeration. Figure 6e shows the Energy dispersive spectroscopy (EDX) of Gd:MgZrO $\mathrm{Mr}_{3}$ (4 mol\%), which clearly indicates that, the material is pure and all the elements $\mathrm{Gd}, \mathrm{O}, \mathrm{Mg}$ and $\mathrm{Zr}$ were clearly seen in the image. The elemental composition obtained from the EDX was in close correlation with that of experimental calculaltion. To examine into the deep insights of elemental composition and oxidation state of the elements, XPS analysis of $\mathrm{Gd}: \mathrm{MgZrO}_{3}(4 \mathrm{~mol} \%)$ was carried out. The core level XPS of Gd shown in Fig. 7a clearly indicates two spin orbit doublets at $1220.2\left(3 \mathrm{~d}_{3 / 2}\right)$ and $1187.5\left(3 \mathrm{~d}_{5 / 2}\right)$, incorporation and existance of $\mathrm{Gd}^{3+}$ was clearly evident from this data [26]. The core Mg $1 \mathrm{~s}$ XPS spectra shows a typical at 1304.6, indicates monooxide form of magnesium as shown in Fig. 7b [27]. XPS of zirconia shows two spin-orbit split doublets (Fig. 7c) at $182 \mathrm{eV}$ and $184.5 \mathrm{eV}$ corresponding to $3 \mathrm{~d}_{5 / 2}$ and $3 \mathrm{~d}_{3 / 2}$ respectively with an energy separation of $2.5 \mathrm{eV}$. Also the full width at half maximum (FWHM) was found to be $1.7 \mathrm{eV}$ for both peaks, these values were in good agreement with the literature reported [28]. Figure $7 \mathrm{~d}$ shows the $\mathrm{O} 1 \mathrm{~s}$ spectra of $\mathrm{Gd}: \mathrm{MgZrO}_{3}(4 \mathrm{~mol} \%)$ positioned at $530.2 \mathrm{eV}$, this clealry indicates the formation of oxides of magnesium and zirconium. Also absence of sattelite peaks clearly indicates that there are no surface hydroxyl groups or physisorbed water molecules, this is due to fact that the material is calcinated at $800^{\circ} \mathrm{C}$.

Photocatalytic experiments of $\mathrm{Gd}: \mathrm{MgZrO}_{3}$ was performed for the degradation of Rhodamine $B$ a cationic dye under UV light irradiation. Before degradation process the catalyst-dye mixture ( $20 \mathrm{mg} \mathrm{I}^{-1}$ of dye) was allowed to attain adsorption-desorption equilibrium for $30 \mathrm{~min}$. The progress of the degradation process was monitored by measuring its UV-vis absorption spectrum. The degradation efficiencies were expressed in terms of percentage of dye degraded, it was found to be $91.6 \pm 3.2$ for Gd:MgZrO (4 mol\%). 4 mol\% of gadolinium doped magnesium zirconate was found to be optimum for photocatalytic degradation of Rhodamine B, beyond this percentage of gadolinium doping will decrease the effective available surface area, thereby decreases the photocatalytic efficiency as shown in Fig. 8a. Kinetics of RhB degradation is another
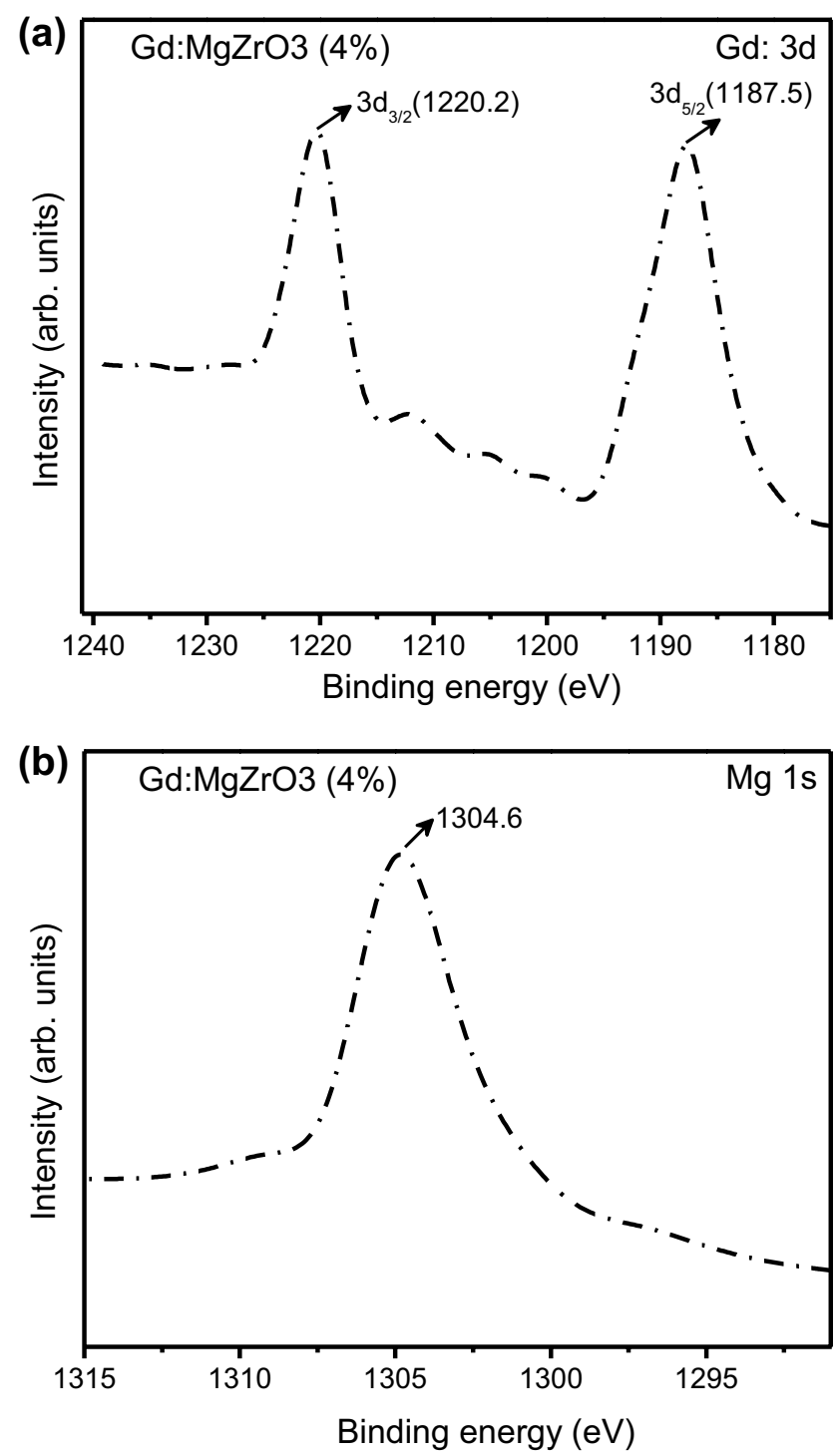

Fig. 7 Core level XPS spectra of a Gd-3d, b Mg-1s, c Zr-3d, d O-1s

important parameter which gives deep insights into the underlying mechanism, more than $75 \%$ of dye underwent degradation within the intial $45 \mathrm{~min}$ (Fig. 8b), this indicates that $\mathrm{RhB}$ degradation follows a peculiar mechanism. For now, RhB shows majorly two different structural forms like lactone and zwitterion forms (Fig. 9) based on the $\mathrm{pH}$ of the solution [29]. The absorption at $259 \mathrm{~nm}$ is arising due to the presence of aromatic rings of Rhodamine $\mathrm{B}$, consequent decrement in the absorption at $259 \mathrm{~nm}$ during the degradation process clearly indicates destruction of aromatic rings. The absorption band at $553 \mathrm{~nm}$ is due to $\mathrm{n} \rightarrow \pi$ transition arising due to carboxyl and imine functional groups present in Rhodamine B, decrease in intensity of this peak indicates breakage and subsequent degradation these groups to form $\mathrm{CO}_{2}$ and $\mathrm{H}_{2} \mathrm{O}$ [30]. From the absorption spectra (inset Fig. $8 \mathrm{~b}$ ) it is clearly evident that, 

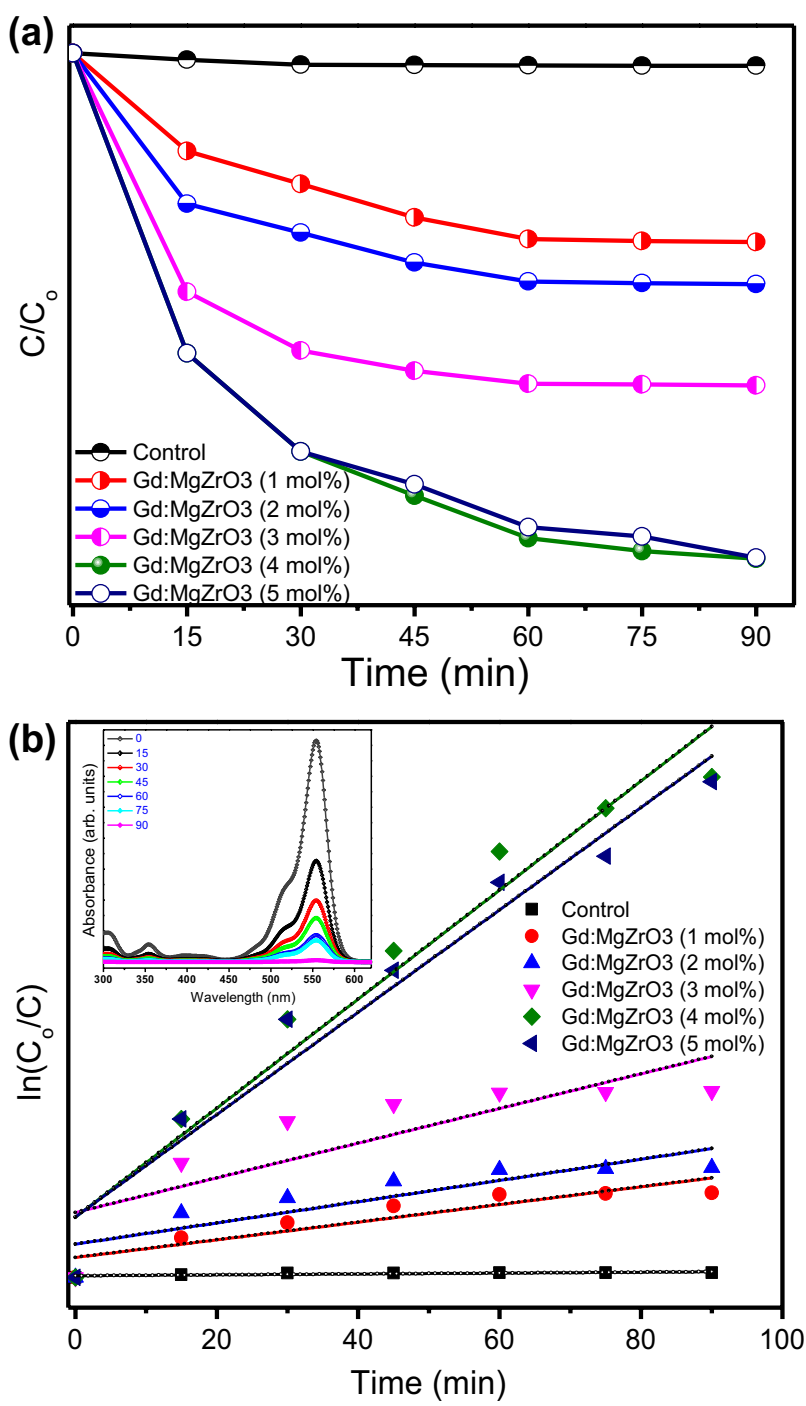

Fig. 8 a Normalized degradation plots of RhB, b Kinetic plots with rate of degradation of RhB (Inset UV-Vis absorption spectra of RhB)

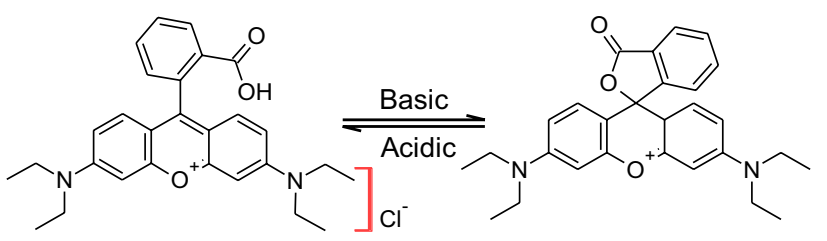

Fig. 9 Lactone and zwitterion forms of Rhodamine $b$

there is no shift in the peak position. This clealry indicates direct destruction of aromatic moeties during the degradation of $\mathrm{RhB}$ at $\mathrm{Gd}: \mathrm{MgZrO}_{3}$ followed by mineralization. Optimization of reaction with respect to the amount of $\mathrm{Gd}: \mathrm{MgZrO}_{3}$ at constant irradiation of light was made, the optimal amount of catalyst was found to be $50 \mathrm{mg}$ with $91.6 \%$ of degradation efficiency with respect to RhB. The reusability of the catalyst was evaluated, after each batch of photocatalytic experiment, the catalyst was washed with ethanol and dried at $120^{\circ} \mathrm{C}$ in an hot air oven. High retention of photocatalytic activity with no significant lose in performance was observed even after five batches of photocatalytic process as shown in Fig. 10.

To know the RhB degradation mechanism at $\mathrm{Gd}: \mathrm{MgZrO}_{3}$, radical trapping experiments were carried out. Ethylene diamine tetraacetic acid (EDTA), benzoquinone (BQ) and iso-propanol (iP) were used to trap holes, electrons and $\cdot \mathrm{OH}$ radicals respectively. Addition of iso-propanol $(72.4 \pm 3.2)$ and benzoquinone $(76.2 \pm 3.0)$ didnot influence much on the kinetics of RhB degradation at $\mathrm{Gd}: \mathrm{MgZrO}_{3}$, however addition of EDTA $(42.4 \pm 3.4)$ decreased the reaction signficantly (Fig. 11a). From this observation it is clealry evident that, participation of photogenerated holes are mainly responsible for the degradation of RhB with minor contribution from electrons and $\cdot \mathrm{OH}$ radicals [31]. The retention of crystal structure of the catalyst was confirmed by recording the XRD of the catalyst after five batches of photocatalytic process as shown in Fig. $11 \mathrm{~b}$. The generation of hydroxide radicals during the photochemical process was further examined by the ESR technique, (5,5-Dimethyl-1-pyrroline N-oxide) DMPO was used as a probe reagent in spin-trap experiments in aqueous solution. As shown in Fig. 12 no DMPO- $\mathrm{OH}$ adducts were detected for the degradation experiment conducted in dark condition in presence of $\mathrm{Gd}: \mathrm{MgZrO}_{3}$. However, under UV irradiation, the characteristic quartet peaks of DMPO-OH with intentsity distribution of (1:2:2:1) are observed. From the ESR characterization it is clearly evident that, involvent oxygeneous radical $(\cdot \mathrm{OH})$ during

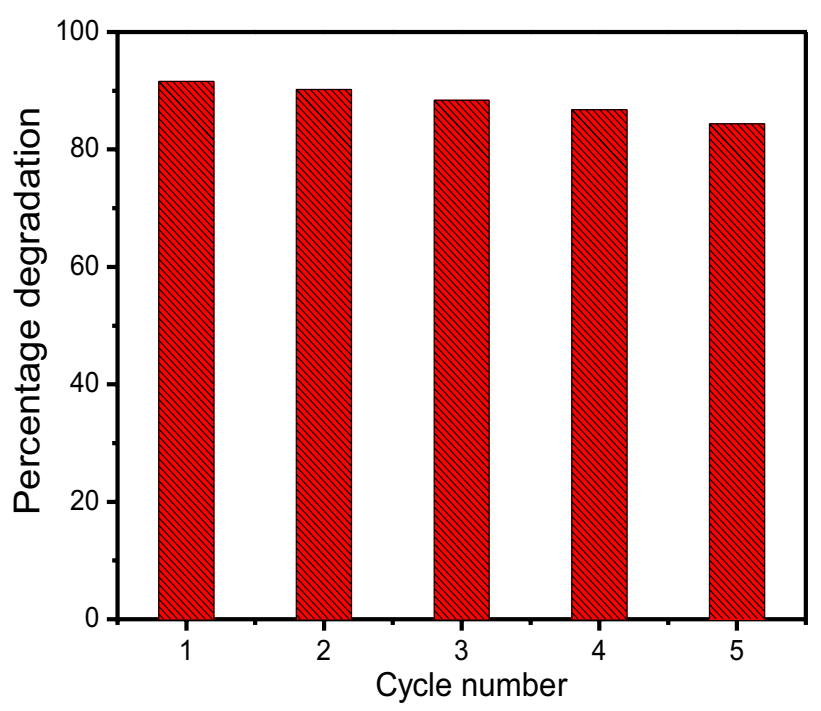

Fig. 10 Reusability test of degradation of RhB at Gd:MgZrO 
(a)
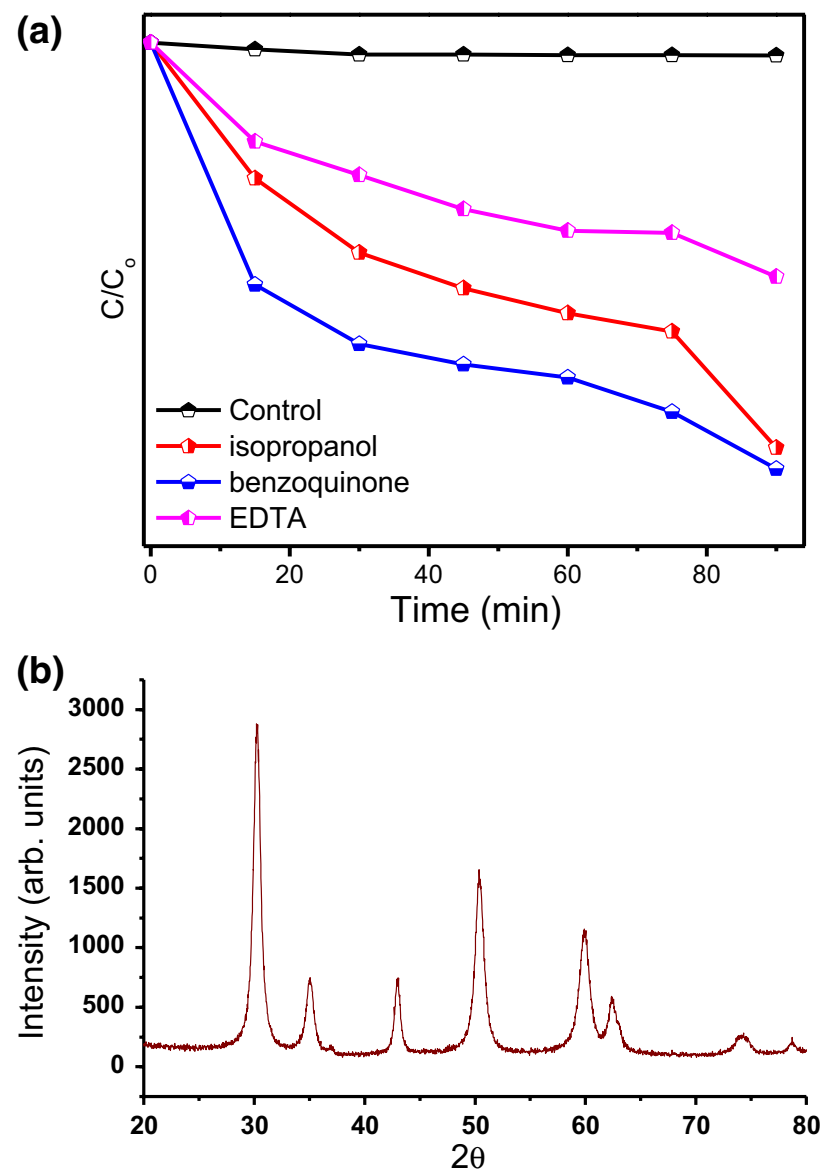

Fig. 11 a Normalized photocatalytic degradation of RhB in presence of scavengers (IP, BQ and EDTA) at Gd:MgZrO. b XRD spectrum of $\mathrm{Gd}: \mathrm{MgZrO}_{3}$ after five cycles of photocatalytic process

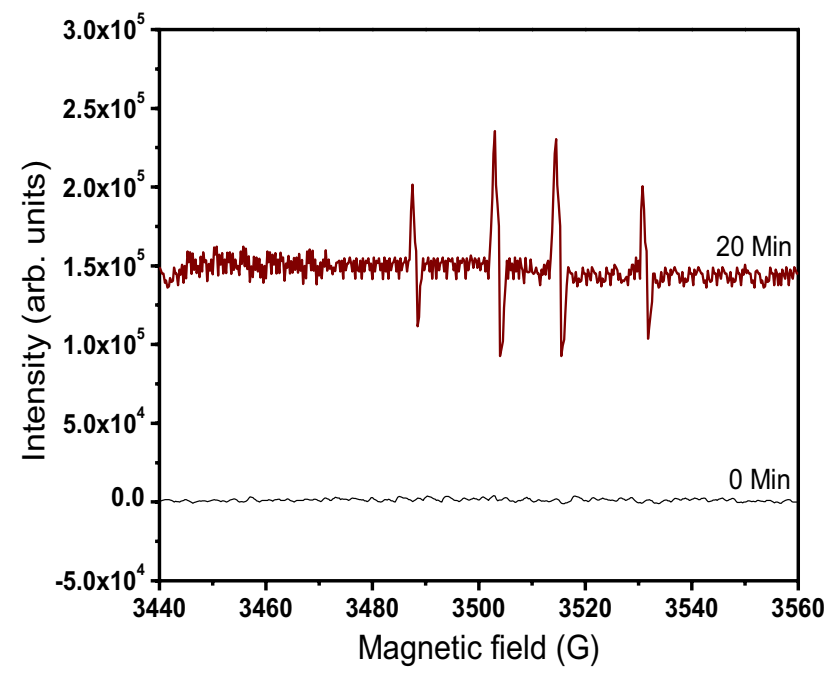

Fig. 12 ESR spectra of hydroxyl radicals-adduct with DMPO at $\mathrm{Gd}: \mathrm{MgZrO}_{3}$ (4 mol\%) in aqueous dispersion under the irradiation of UV light ( $\left.254 \mathrm{~nm}, 500 \mathrm{~mW} / \mathrm{cm}^{2}\right)$. Volume-2 mL, Gd:MgZrO $3-4 \mathrm{mg}$, DMPO-0.22 M the photocatalytic degradation of Rhodamine $B$ in water at Gd:MgZrO .

To know the nature of charge tranfer and rate of recombination of electron-hole pairs, photoluminescence spectra of $\mathrm{Gd}: \mathrm{MgZrO}_{3}$ has been recorded. The PL spectra of $\mathrm{Gd}: \mathrm{MgZrO}_{3}$ excited at $\lambda_{\text {excitation }}=270 \mathrm{~nm}$ has been shown in Fig. 13. The photons with this energy can bring about the tranistion between the valence and conduction states. From the spectra it is clearly evident that, combination of $\mathrm{Gd}$ (Valence + 3), Mg(Valence + 2) with Zr (Valence + 4) will create more oxygen vacancy defects to excite more F-centers, this would result in improved luminescence intensity (Inset of Fig. 13). The energy peaks positioned at $2.93 \mathrm{eV}$ and $2.79 \mathrm{eV}$ are due to the singly ionized vacancy centers $\left(\mathrm{Vo}^{+}\right)$and arised due to multiple luminescence centers. The band at $3.36 \mathrm{eV}$ is due to the cumulative effect of uneven distribution of $\mathrm{Zr}^{4+}$ at near surface sites, which arise due to the dangling bonds on the surface of the material and due to the radiative recombination of electrones and holes in gadolinium centers. The green emission at $2.24 \mathrm{eV}$ is due to ${ }^{6} \mathrm{G}$, to $\mathrm{Gd}^{3+}$ transition that arise due to stark level manifolds [32-36]. From PL studies it is found that combination of $\mathrm{Gd}, \mathrm{Mg}$ and $\mathrm{Zr}$ resulted in high oxygen vacancy in the material, this made the $\mathrm{Gd}: \mathrm{MgZrO}_{3}$ a robust photocatalyst for the degradation of RhB.

Degradation of Rhodamine $B$ is achieved by the interaction of $\mathrm{RhB}$ with the photogenerated holes of $\mathrm{Gd}: \mathrm{MgZrO}_{3}$, the recombination of these photogenerated electron-holes will be restrained due to the creation of $4 \mathrm{f}$ trap centers created by $\mathrm{Gd}^{3+}$ ions (Fig. 14), this mechanism leads to the $p-n$ junction like set up. In total the electron-hole recombination is effectively suppresed by the synergism arising by the combination of $\mathrm{Gd}, \mathrm{Mg}$

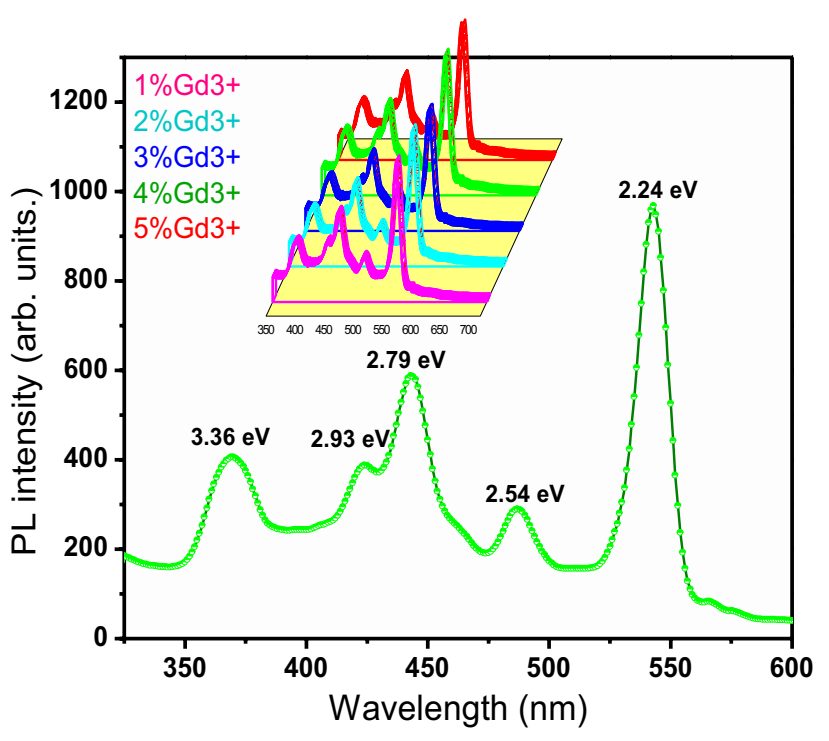

Fig. 13 Photoluminescence spectra of Gd:MgZrO 3 (1-5 mol\%) 


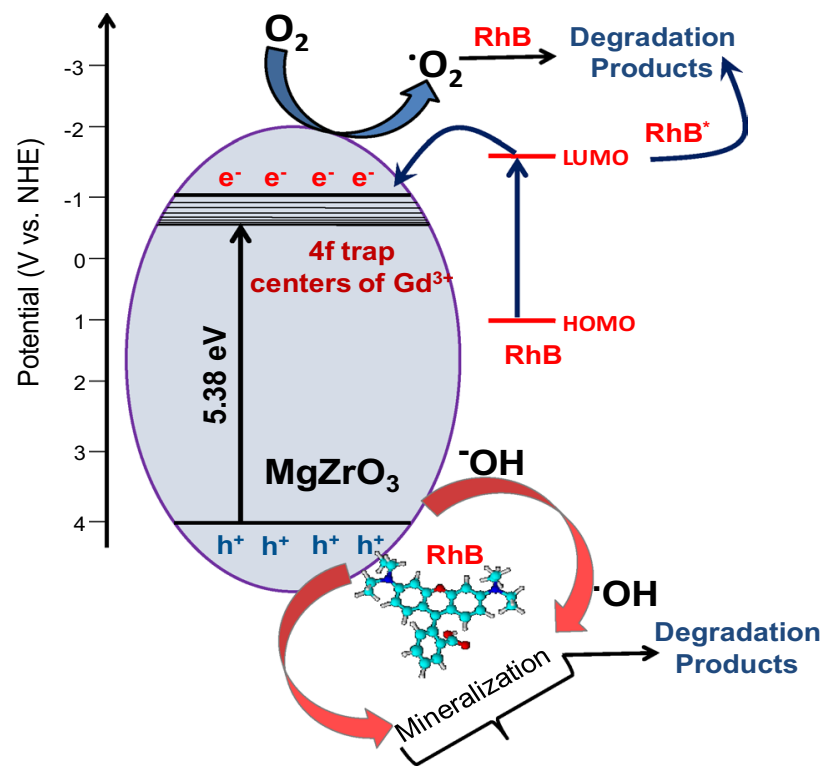

Fig. 14 Proposed mechanism of degradation of $\mathrm{RhB}$ at $\mathrm{Gd}: \mathrm{MgZrO}_{3}$

and Zr. From the experimental investigation it is evident that, the photogenerated holes and electrons are arising either from the $\mathrm{Gd}: \mathrm{MgZrO}_{3}$ material or Rhodamine $\mathrm{B}$ dye. Finally it is clearly proved that, the degradation of $\mathrm{RhB}$ is majorly governed by (i) interaction of $\mathrm{RhB}$ with the photogenerarated holes in $\mathrm{Gd}: \mathrm{MgZrO}_{3}$ and with minor contribution from (ii) lonization of $\mathrm{O}_{2}$ and its interaction with RhB (iii) Transfer of electrons from LUMO levels of photoexcited RhB to the conduction band or defect levels of $\mathrm{Gd}: \mathrm{MgZrO}_{3}$ followed by mineralization.

\section{Conclusions}

Nanoscale disc like gadolinium doped magnesium zirconate was prepared by simple solvothermal process. Optimization of reaction conditions revealed that, $4 \mathrm{~mol} \%$ $\mathrm{Gd}: \mathrm{MgZrO}_{3}$ was effective for the photocatalytic degradation of Rhodamine B than other combinations. The robust photocatalytic efficiency is due to the synergistic effect arising due to high defect centers created by the combination of these elements. When the precursors are processed by solvothermal protocol for three days lead to the formation of disc like Gd:MgZrO high degradation efficiency against the cationic dye RhB (91.6\%), good reusability and stability. All these properties makes $\mathrm{Gd}: \mathrm{MgZrO}_{3}$ a competent mateial in environmental remediation.

\section{Compliance with ethical standards}

Conflict of interest The authors declare that they have no conflicts of interest.

\section{References}

1. Lellis B, Fávaro-Polonio CZ, Pamphile JA, Polonio JC (2019) Effects of textile dyes on health and the environment and bioremediation potential of living organisms. Biotechnol Res Innov 3:275-290. https://doi.org/10.1016/j.biori.2019.09.001

2. Ahmad A, Mohd-Setapar SH, Chuong CS, Khatoon A, Wani WA, Kumar R, Rafatullah M (2015) Recent advances in new generation dye removal technologies: novel search for approaches to reprocess wastewater. RSC Adv 5:30801-30818. https://doi. org/10.1039/c4ra16959j

3. Saleem J, Bin Shahid U, Hijab M, Mackey H, McKay G (2019) Production and applications of activated carbons as adsorbents from olive stones. Biomass Convers Biorefinery 9:775-802. https ://doi.org/10.1007/s13399-019-00473-7

4. Saritha V, Karnena MK, Dwarapureddi BK (2020) Competence of blended coagulants for surface water treatment. Appl Water Sci 10:20. https://doi.org/10.1007/s13201-019-1108-4

5. Srivastava S, Vaddadi S, Kumar P, Sadistap S (2018) Design and development of reverse osmosis (RO) plant status monitoring system for early fault prediction and predictive maintenance. Appl Water Sci 8:1-10. https://doi.org/10.1007/s1320 1-018-0821-8

6. Loeb SK, Alvarez PJJ, Brame JA, Cates EL, Choi W, Crittenden J, Dionysiou DD, Li Q, Li-Puma G, Quan X, Sedlak DL, David Waite T, Westerhoff P, Kim JH (2019) The technology horizon for photocatalytic water treatment: sunrise or sunset? Environ Sci Technol 53:2937-2947. https://doi.org/10.1021/acs.est.8b05041

7. Zaleska-Medynska A, Marchelek M, Diak M, Grabowska E (2016) Noble metal-based bimetallic nanoparticles: the effect of the structure on the optical, catalytic and photocatalytic properties. Adv Colloid Interface Sci 229:80-107. https://doi.org/10.1016/j. cis.2015.12.008

8. Wali LA, Alwan AM, Dheyab AB, Hashim DA (2019) Excellent fabrication of Pd-Ag NPs/PSi photocatalyst based on bimetallic nanoparticles for improving methylene blue photocatalytic degradation. Optik 179:708-717. https://doi.org/10.1016/j.ijleo .2018.11.011

9. Sharma G, Gupta VK, Agarwal S, Bhogal S, Naushad M, Kumar A, Stadler FJ (2018) Fabrication and characterization of trimetallic nano-photocatalyst for remediation of ampicillin antibiotic. J Mol Liq 260:342-350. https://doi.org/10.1016/j.molli q.2018.03.059

10. Kumar D, Awasthi GP, Park CH, Kim CS (2018) Multifunctional trimetallic colloidal plasmonic nanohybrid: highly efficient photocatalyst and photothermal agent. Adv Mater Interfaces 5:1-7. https://doi.org/10.1002/admi.201800331

11. Kumar KY, Saini H, Pandiarajan D, Prashanth MK, Parashuram $\mathrm{L}$, Raghu MS (2018) Controllable synthesis of $\mathrm{TiO}_{2}$ chemically bonded graphene for photocatalytic hydrogen evolution and dye degradation. Catal Today. https://doi.org/10.1016/j.catto d.2018.10.042

12. Yoo JE, Lee K, Altomare M, Selli E, Schmuki P (2013) Self-organized arrays of single-metal catalyst particles in $\mathrm{TiO}_{2}$ cavities: a highly efficient photocatalytic system. Angew Chemie Int Ed 52:7514-7517. https://doi.org/10.1002/anie.201302525

13. Rao T, Saladino ML, Wang X, Fang Y, Giordano C (2019) Multimetallic oxynitrides nanoparticles for a new generation 
of photocatalysts. Chemistry 25:16676-16682. https://doi. org/10.1002/chem.201904033

14. Jiang L, Li J, Wang K, Zhang G, Li Y, Wu X (2020) Environmental low boiling point solvent mediated strategy to synthesize functionalized monolayer carbon nitride for superior photocatalytic hydrogen evolution. Appl Catal B 260:118181. https://doi. org/10.1016/j.apcatb.2019.118181

15. Jiang T, Wang K, Guo T, Wu X, Zhang G (2020) Fabrication of Z-scheme $\mathrm{MoO}_{3} / \mathrm{Bi}_{2} \mathrm{O}_{4}$ heterojunction photocatalyst with enhanced photocatalytic performance under visible light irradiation. Chin J Catal 41:161-169. https://doi.org/10.1016/S1872 -2067(19)63391-7

16. Parashuram L, Sreenivasa $S$, Akshatha $S$, Kumar VU, Kumar $S$ (2017) Zirconia-supported Cu(I)-stabilized copper oxide mesoporous catalyst for the synthesis of quinazolinones under ambient conditions. Asian J Org Chem 6:1755-1759. https://doi. org/10.1002/ajoc.201700467

17. Parashuram L, Sreenivasa S, Akshatha S, Udayakumar V, Sandeep Kumar A (2019) A non-enzymatic electrochemical sensor based on $\mathrm{ZrO}_{2}: \mathrm{Cu}(\mathrm{I})$ nanosphere modified carbon paste electrode for electro-catalytic oxidative detection of glucose in raw Citrus aurantium var. sinensis. Food Chem 300:125178. https://doi. org/10.1016/j.foodchem.2019.125178

18. Dhandapani C, Narayanasamy R, Karthick SN, Hemalatha KV, Selvam S, Hemalatha P, Suresh M, Kirupha SD, Kim H (2016) Drastic photocatalytic degradation of methylene blue dye by neodymium doped zirconium oxide as photocatalyst under visible light irradiation. Opt Int J Light Electron Opt 127:10288-10296. https ://doi.org/10.1016/j.ijleo.2016.08.048

19. Parashuram L, Sreenivasa S, Akshatha SR, Kumar VU, Kumar S (2019) Environmentally benign approach for the synthesis of Azo dyes in the presence of mesoporous sulfated core-shell zirconia-copper(I) oxide solid acid catalyst. ChemistrySelect 4:5097-5105. https://doi.org/10.1002/slct.201803295

20. Shim JH, Chao CC, Huango H, Prinz FB (2007) Atomic layer deposition of yttria-stabilized zirconia for solid oxide fuel cells. Chem Mater 19:3850-3854. https://doi.org/10.1021/cm070913t

21. Huang Z, Han W, Feng Z, Qi J, Wu D, Wei N, Tang Z, Zhang Y, Duan J, Lu T (2019) The effects of precipitants on co-precipitation synthesis of yttria-stabilized zirconia nanocrystalline powders. J Sol-Gel Sci Technol 90:359-368. https://doi.org/10.1007/s1097 1-019-04947-y

22. Chang Y, Wang C, Liang T, Zhao C, Luo X, Guo T, Gong J, Wu H (2015) Sol-gel synthesis of mesoporous spherical zirconia. RSC Adv 5:104629-104634. https://doi.org/10.1039/c5ra23782c

23. Akshatha S, Sreenivasa S, Parashuram L, Udaya Kumar V, Sharma SC, Nagabhushana H, Kumar S, Maiyalagan T (2019) Synergistic effect of hybrid $\mathrm{Ce}^{3+} / \mathrm{Ce}^{4+}$ doped $\mathrm{Bi}_{2} \mathrm{O}_{3}$ nano-sphere photocatalyst for enhanced photocatalytic degradation of alizarin red $\mathrm{S}$ dye and its NUV excited photoluminescence studies. J Environ Chem Eng 7:103053. https://doi.org/10.1016/j.jece.2019.10305 3

24. Sagadevan S, Podder J, Das I (2016) Hydrothermal synthesis of zirconium oxide nanoparticles and its characterization. J Mater
Sci Mater Electron 27:5622-5627. https://doi.org/10.1007/s1085 4-016-4469-6

25. Liu X, Pappas I, Fitzgerald M, Zhu Y, Eibling M, Pan L (2010) Solvothermal synthesis and characterization of $\mathrm{ZrO}_{2}$ nanostructures using zirconium precursor. Mater Lett 64:1591-1594. https://doi. org/10.1016/j.matlet.2010.04.044

26. Barreca D, Gasparotto A, Milanov A, Tondello E, Devi A, Fischer RA (2007) $\mathrm{Gd}_{2} \mathrm{O}_{3}$ nanostructured thin films analyzed by XPS. Surf Sci Spectra 14:60-67. https://doi.org/10.1116/11.20080703

27. Ardizzone S, Bianchi CL, Fadoni M, Vercelli B (1997) Magnesium salts and oxide: an XPS overview. Appl Surf Sci 119:253-259. https://doi.org/10.1016/S0169-4332(97)00180-3

28. Sinhamahapatra A, Jeon J, Kang J, Han B, Yu J (2016) Oxygendeficient zirconia $\left(\mathrm{ZrO}_{2}-\mathrm{x}\right)$ : a new material for solar light absorption. Sci Rep 6:1-8. https://doi.org/10.1038/srep27218

29. Hinckley DA, Seybold PG (1988) A spectroscopic/thermodynamic study of the rhodamine $B$ lactone e zwitterion equilibrium. Spectrochim Acta Part A 44:1053-1059

30. Chen X, Xue Z, Yao Y, Wang W, Zhu F, Hong C (2012) Oxidation degradation of rhodamine $B$ in aqueous by UV/S2O82treatment system. Int J Photoenergy 2012:1-5. https://doi. org/10.1155/2012/754691

31. Sharma M, Vaidya S, Ganguli AK (2017) Enhanced photocatalytic activity of g-C3N4-TiO2 nanocomposites for degradation of Rhodamine B dye. J Photochem Photobiol A 335:287-293. https://doi.org/10.1016/j.jphotochem.2016.12.002

32. Tamrakar RK, Bisen DP, Brahme N (2014) Comparison of photoluminescence properties of $\mathrm{Gd}_{2} \mathrm{O}_{3}$ phosphor synthesized by combustion and solid state reaction method. J Radiat Res Appl Sci 7:550-559. https://doi.org/10.1016/j.jrras.2014.09.005

33. Manjunatha S, Dharmaprakash MS (2012) Thermal stability, optical and Photoluminescence properties of spherical CexZr1- $\mathrm{xO}_{2}$ $(x=005)$ crystalline blue-emitting nanophosphors synthesized by microwave method. Mater Res Express 2:1-46

34. Liang J, Deng Z, Jiang X, Li F, Li Y (2002) Photoluminescence of tetragonal $\mathrm{ZrO}_{2}$ nanoparticles synthesized by microwave irradiation. Inorg Chem 41:3602-3604. https://doi.org/10.1021/ ic025532q

35. Zhang $\mathrm{H}, \mathrm{Fu} X, \mathrm{Niu} \mathrm{S}$, Xin Q (2008) Blue emission of $\mathrm{ZrO}_{2}: \mathrm{Tm}$ nanocrystals with different crystal structure under UV excitation. J Non Cryst Solids 354:1559-1563. https://doi.org/10.1016/j. jnoncrysol.2007.08.064

36. Emeline A, Kataeva GV, Litke AS, Ryabchuk VK, Rudakova AV, Serpone N (1998) Spectroscopic and photoluminescence studies of a wide band gap insulating material: powdered and colloidal $\mathrm{ZrO}_{2}$ sols. Langmuir 14:5011-5022. https://doi.org/10.1021/ la980083|

Publisher's Note Springer Nature remains neutral with regard to jurisdictional claims in published maps and institutional affiliations. 